\title{
Can Dietary Method Replace the 24 hours Urinary Sodium Excretion Method of Assessing Sodium Consumption at Population Level?
}

\author{
Sonal Dhemla* and Kanika Varma \\ Department of Home Science, University of Rajasthan, Jaipur, India
}

Received: 制: November 16, 2018; Published: 鴊: November 26, 2018

*Corresponding author: Sonal Dhemla, Department of Home Science, University of Rajasthan, Jaipur, India

\begin{abstract}
Objective: Assessment of sodium consumption at population level and to explore the usefulness of the method by comparing the sodium assessment by dietary recall method with sodium excretion in 24-hour urine sample.

Methods: Two hundred subjects were selected by purposive sampling on the basis of selection criteria. Sodium consumption was assessed by self reported 24 hour dietary recall method and through assessment of sodium excreted in 24 hours urine sample.

Results: The mean sodium consumption assessed by dietary method and 24 hours urinary sodium excretion was $(3840.6 \pm 1810.1$ and $4796.3 \pm 3303.3 \mathrm{mg} /$ day respectively) very high. Sodium consumption obtained by two mentioned methods was significantly different.

Discussion and conclusion: The average sodium intake was very high than the recommended intake. The sodium intake assessed by dietary method was found to be under-estimated. Twenty four hours urinary sodium excretion can be the best method to measure sodium consumption at population level.
\end{abstract}

Keywords: Sodium; Salt; Urinary Sodium Excretion; Dietary Sodium Intake; Hypertension

\section{Introduction}

Cardiovascular diseases (CVD) account for a large proportion of all deaths and disability all over the world [1]. The Global Burden of Diseases study has reported that hypertension is the most important cardiovascular risk factor in this region and responsible for the largest burden of disease and mortality [1]. Global Burden of Diseases study reported that hypertension led to 1.63 million deaths in India in 2016 as compared to 0.78 million in 1990 indicating 108\% increase in prevalence [2]. The disease burden (DALYs) attributable to hypertension increased from 21 million in 1990 to 39 million in 2016, again increased by $89 \%$ [2]. Rajasthan had second highest cases of hypertension $(345,770)$ as assessed by National Health Profile from January to December 2017 [3]. Various risk factors including high salt intake and so many are associated with hypertension in developing countries [4]. The study of the Indian Council of Medical Research-India Diabetes (ICMR-INDIAB) underlined that those who consumed more than $6.5 \mathrm{~g}$ per day of salt had a significantly higher risk of developing hypertension as compared to those who consumed less than the median intake of salt in the population studied [5].

Most of the adult populations all-over the world is consuming an average daily salt intake more than 6 gram/day; with salt consumption higher than 12 grams in Eastern Europe and Asia. National and International recommendations recommended the average population salt intake of less than 5-6 gram/day [6-8]. India is undergoing an epidemiological transition and is on the threshold of an epidemic of cardiovascular disease. The rising burden of hypertension, associated CVD and NCDs in India needs to be addressed as a public health priority. It is the time to defend against the continuous growing threat of hypertension which further leads to cardiovascular diseases in India. It is imperative to determine current consumption levels so that appropriate evidence-based preventative public health action can be initiated.

Numerous methods can be used to estimate sodium intake at population level: duplicate diets, dietary surveys and urinary sodium 
excretion. Twenty-four hour urine collection is a recommended method of monitoring population sodium intake $[9,10]$.

In contrast, dietary methods (e.g., 24-h dietary recalls, food frequency questionnaires, dietary records) can be biased by errors in recall and recording as well as errors in food and nutrient composition tables [11]. Dietary methods also do not usually capture the amount of sodium from salt added at the table or the amount of sodium consumed from non-dietary sources [12]. Thus the study was designed to estimate sodium intake at population level, and to explore the usefulness of the method by comparing the sodium intake by dietary assessment with sodium excretion in 24hour urine samples.

\section{Methods and Materials \\ Locale of the Study}

The study was conducted in Jaipur, a capital city of Rajasthan state in India. Rajasthan has a mouth watering and diverse dietary culture where salt and spices are used extensively. As per the social practices in the region, people do consume diets rich in salt. Along with the current consumption pattern, it seems to be converging towards a Western diet too.

\section{Sample Selection}

Two hundred healthy, 25-45 years old subjects were selected by purposive sampling. Informed consent was taken first from all the subjects. Subject's cooperation was very essential; as 24-hours urine excretion collection of all the subjects along with its accuracy was the requirement of the study. Potential participants were then selected on the basis of selection criteria. Once a subject was selected, house visits were made to collect the data. Their informed consent was taken before conducting any data collection. Ethical clearance was obtained by the Ethical Committee of the Home Science Department, University of Rajasthan, Jaipur.

\section{Data collection}

Personal particulars of the subjects were taken by using self developed pre-tested interview schedule.

\section{Anthropometric Assessment}

Height $(\mathrm{cm})$, weight $(\mathrm{kg})$, waist and hip circumferences $(\mathrm{cm})$ were taken and BMI and WHR were further calculated by using observed parameters. Finally they were interpreted as per their respective given cutoff values [13,14]. Body fat percentage was measured by using OMRON Body Fat Monitor model HBF-306, which was further used to calculate fat free mass used to confirm the completeness of urine sample collected.

\section{Dietary Assessment of Sodium}

In present study information regarding the dietary pattern of subjects was gathered by using 24-hour dietary recall for three days including one holiday. The sodium content of these diets was then calculated by using "Dietcal" software based on "Indian
Food Composition Tables" [15]. A Qualitative Food Frequency Questionnaire was also used to determine how often certain foods were eaten. All dietary data was taken by a trained nutritionist.

\section{Hours Urinary Sodium Excretion Assessment}

Dietary methods for measuring sodium consumption are challenging, mostly due to their limited ability to capture the discretionary uses of salt. Dietary consumption studies therefore typically underestimate the true salt intake [16-18]. Twenty four hour urinary sodium excretion was advocated by WHO as a gold standard method to estimate sodium consumption in the population [8]. Considering that $85 \%$ of the sodium intake is excreted in the urine, 24-h urine excretion has been used as a marker for daily sodium consumption [8]. Respondents were provided with a $500 \mathrm{ml}$ beaker with a wide opening, funnel to be used during urine collection and a five liters screw capped plastic bottles-the collection container (without any preservative). Subjects were given verbal and written about the procedure to collect urine into the container. During the collection period, participants were instructed to store the storage container in a cool and dark place, away from heat or sun.

Urine containers were scheduled for prompt return to the laboratory for analysis. Assessments were carried out at a clinical laboratory by trained technicians, and the secondary data were used for the purpose.

\section{Completeness of urine sample collected}

An assessment of completeness of the urine sample was carried out by estimating the creatinine content of the urine. For the purpose, correlation between urinary creatinine and the muscular mass of each subject was taken into account. Fat-free mass (FFM-C) was therefore calculated bearing in mind the creatinine excreted in the $24 \mathrm{~h}$ urine using the following equation [19]. Fat-free mass $(\mathrm{kg})=0.02908 \times$ creatinine $(\mathrm{mg} / \mathrm{d})+7 \cdot 38$. The results were compared with the fat-free mass results obtained by the electrical bio-impedance method (FFM-EBI). An association between FFMEBI and FFM-C was supposed to confirm the completeness of urine.

\section{Statistical Analysis}

Data was analyzed by using frequency and percent distribution, arithmetic mean, standard deviation (SD), paired " $\mathrm{t}$ " test, correlation coefficient as desired for the set of data. All calculations were made by using IBM SPSS software.

\section{Results}

\section{General Profile}

General profile of the subjects illustrated that maximum of the subjects (88.0\%) belonged to upper middle Socio Economic Status. Seventy two percent of the subjects were vegetarian and others were also consuming non-vegetarian food very infrequently. Focusing on the family history of hypertension, 52.5\% subjects had disease history either from paternal, maternal or both side. When 
subjects were enquired about consanguineous presence of other heart disease, $34.5 \%$ subjects responded positively.

\section{Anthropometric Measurements}

Mean anthropometric measurements of the subjects are presented in Table 1. Figures generated indicated that all mean anthropometric measures were towards higher sides both in men and women. Evidences reported the association of extended anthropometry measurements with hypertension [20,21], cardiovascular risk and metabolic syndromes [22-24], heart failure [25,26] and diabetes [26,27]. A WHO expert consultation [14]

reviewed scientific evidence that suggested Asian populations have different associations between BMI, percentage of body fat, and health risks than do European populations. As stated earlier that the consultation concluded that the proportion of Asian people with a high risk of type 2 diabetes and cardiovascular disease is substantial at BMIs lower than the existing WHO cut-off point for overweight ( $\geq 25 \mathrm{~kg} / \mathrm{m}^{2}$ ) [14]. Studies from northern parts of India $[28,29]$ had shown that the normal BMI for an Indian was $22 \mathrm{~kg} / \mathrm{m}^{2}$ and supported the view that a BMI of $23.0 \mathrm{~kg} / \mathrm{m}^{2}$ might be ideal for the Asian Indian population.

Table 1: Mean anthropometric measurements of subjects according to their age and gender groups.

\begin{tabular}{|c|c|c|c|c|}
\hline S.No & Parameters & Total men $(\mathbf{n = 1 0 0})$ & Total women $(\mathbf{n}=\mathbf{1 0 0})$ & Total subjects (n= 200) \\
\hline 1 & Height $(\mathrm{cm})$ & $170.6 \pm 6.1$ & $158.7 \pm 5.9$ & $164.6 \pm 8.5$ \\
\hline 2 & Weight $(\mathrm{kg})$ & $76.3 \pm 11.1$ & $65.1 \pm 10.8$ & $70.7 \pm 12.3$ \\
\hline 3 & BMI $\left(\mathrm{kg} / \mathrm{m}^{2}\right)$ & $26.3 \pm 3.5$ & $25.9 \pm 4.1$ & $26.1 \pm 3.8$ \\
\hline 4 & Waist circumference $(\mathrm{cm})$ & $91.5 \pm 8.6$ & $83.1 \pm 9.6$ & $87.3 \pm 10.0$ \\
\hline 5 & Hip circumference $(\mathrm{cm})$ & $100.7 \pm 8.2$ & $101.5 \pm 7.6$ & $101.1 \pm 7.9$ \\
\hline 6 & WHR & $0.91 \pm 0.06$ & $0.81 \pm 0.06$ & $0.86 \pm 0.07$ \\
\hline
\end{tabular}

Mean BMI of subjects belonging to different age groups was found to be $26.1 \pm 3.8 \mathrm{~kg} / \mathrm{m}^{2}$. Results indicated the prevalence of overweight and obesity in subjects in both genders (Table 1). When the prevalence of general obesity was assessed by the cutoff values given by WHO [14] for global population, near about half $(47.5 \%)$ of the total subjects were found to be pre obese. Only $37.5 \%$ of subjects had normal BMI (i.e. 18.50-24.99). Fourteen percent of subjects were found existing in various classes of obesity. Data assessed according to the classification given for Asian population revealed that $77.0 \%$ of subjects were exceeding the normal range of BMI. Only $22.0 \%$ of subjects had normal BMI, indicating the high prevalence of general obesity (Figure 1). The average WC of the men was $91.5 \pm 8.6 \mathrm{~cm}$, which was found to be exceeding the cut-off values recommended for adult men $(90 \mathrm{~cm})$ by WHO [13].

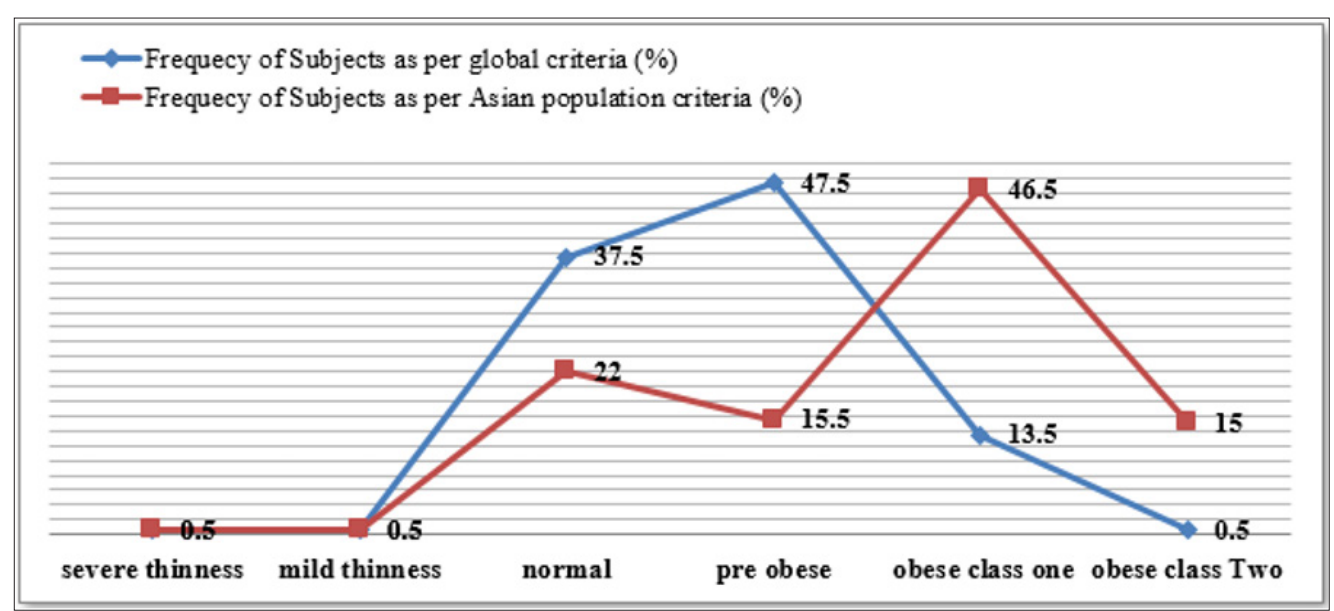

Figure 1: Comparative prevalence of general obesity for Global and Asian population Criteria.

Same trend was also seen in women $(83.1 \pm 9.6 \mathrm{~cm}$ in comparison to $80 \mathrm{~cm}$ ). Prevalence of central obesity defined as WC $\geq 80 \mathrm{~cm}$ in women and $\geq 90 \mathrm{~cm}$ in men was as high as $64.0 \%$ in women and $60.0 \%$ in men. Total $62.0 \%$ subjects had abdominal obesity. Mean hip circumference of subjects was $101.1 \pm 7.9 \mathrm{~cm}$. As seen in case of WC, HC was also found to be higher, although as with other anthropometric variables, there is no cut-off value given for HC. Average WHR for studied population was $0.91 \pm 0.06$ for men and $0.81 \pm 0.06$ for women indicating the higher prevalence of abdominal obesity in subjects. The prevalence of abdominal obesity in subjects was very high i.e. half of the men and $57.0 \%$ women subjects had WHR more than 0.9 and 0.8 respectively.

\section{Dietary Assessment of Sodium}

Sodium intake is of great concern in present scenario due to increased prevalence of heart diseases which is proved to be associated with high sodium intake. Mean sodium intake reported by the subjects in the study was $3840.6 \pm 1810.1 \mathrm{mg} /$ day obtained through 24 hours dietary recall method (Table 2). No any significant difference was observed among gender groups $(p=0.000)$. Further 
analysis revealed that mean sodium naturally present in food was $749.2 \pm 177.8 \mathrm{mg} /$ day, whereas salt $(\mathrm{NaCl})$ was contributing $3091.4 \pm 900.7 \mathrm{mg} /$ day of sodium. It means $80.5 \%$ of sodium was coming from salt added in food during cooking or on the table Table 2: Sodium consumption of subjects assessed through 24 hours dietary recall for three days.

\begin{tabular}{|c|c|c|c|}
\hline Variable & Men $\mathbf{n = 1 0 0}$ & Women $\mathbf{~ = 1 0 0}$ & Total $\mathbf{n}=\mathbf{2 0 0}$ \\
\hline \multirow{2}{*}{ Dietary Sodium intake (mg/day) } & 3769.6 & 3822.8 & 3840.6 \\
\cline { 2 - 4 } & \pm 1725.9 & \pm 1690.4 & \pm 1810.1 \\
\hline
\end{tabular}

\section{$\square$ Sodium contributed by salt $\square$ Sodium from natural food sources}

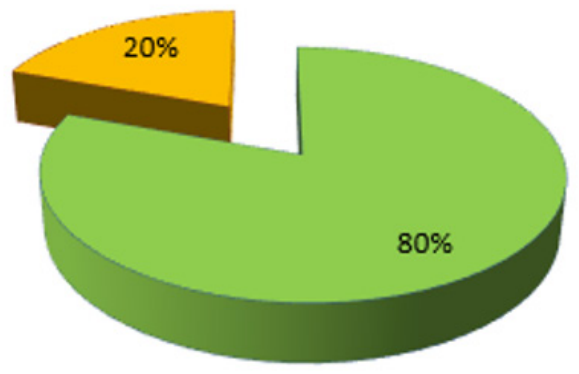

Figure 2: Contribution of sodium by different sources.

\section{Salt Consumption Among Subjects on The Basis Of Monthly Household Consumption Of Salt}

As salt consumption is a sensitive issue and there was a probability of over or under reporting, the monthly consumption of salt was also recorded as reported by the subjects. Most of the subjects reported the tentative amount of monthly salt consumption. They even did not noticed the amount as they used to purchase it in bulk as it is economically cheap and easily available and used in plenty too. Recorded salt consumption was then divided by adult consumption unit [30] to get the consumption at individual level. It was interpreted from outcomes that subjects were consuming on an average $1607 \pm 1617 \mathrm{gm}$ (1.6 kg) of salt per month at household
(Figure 2). When compared with recommended intake of sodium (2000 mg/day) as given by WHO [8], 188.5\% to $191 \%$ of sodium intake was reported by both gender groups.

Table 3: Comparison between sodium intakes obtained by dietary method and monthly household consumption of salt.

\begin{tabular}{|c|c|c|c|c|}
\hline S. No & Variables & Mean \pm SD & t value & Level of significance \\
\hline 1. & $\begin{array}{c}\text { Sodium intake obtained from salt assessed by dietary } \\
\text { method (mg/day) }\end{array}$ & $3091.4 \pm 900.7$ & -2.77 & \multirow{2}{*}{$0.006^{* *}$} \\
\hline 2. & $\begin{array}{c}\text { Sodium intake obtained by monthly household } \\
\text { consumption of salt (mg/day) }\end{array}$ & $3371.4 \pm 1036.4$ & \\
\hline
\end{tabular}

Note: **Significant at 0.01 level

\section{Estimation of Sodium Consumption by Using 24 Hour Urinary Excretion of Sodium}

\section{Urine volume}

Mean urine volume of subjects was $1712.6 \pm 1021.3 \mathrm{ml} /$ day (1855.2 $\pm 1055.6 \mathrm{v} / \mathrm{s} 1570 \pm 970.2$ in men and women). A nonsignificant difference was found between mean urine volume of men and women ( $p=0.039)$. level. When further individual salt consumption was calculated on consumption unit basis [30], overall average consumption was around $8.4 \pm 2.6 \mathrm{gm} /$ day. Intakes were exceeding the recommended consumption in terms of salt, i.e. $5 \mathrm{gm} /$ day. Further, when the values were converted to sodium, it was equivalent to $3371.4 \pm 1036.4 \mathrm{mg} /$ day.

Sodium intake obtained by dietary method was $3840.6 \pm 1810.1$ $\mathrm{mg} /$ day. A significant difference was observed between means of two variables (Table 3 ) as obtained by paired t test. However, a significant correlation was obtained between sodium calculated on the basis of household consumption of salt and salt consumption obtained by dietary method $(\mathrm{r}=0.63 ; \mathrm{p}=0.000)$. 
cereals, vegetables, pulses and milk and milk products. They had been instructed not to change their diet. There was no intense physical exercise during the study period. A significant difference was observed in creatinine excretion of the two different genders $(p=0.000)$. When completeness of urine was assessed on the basis of calculating Pearson's Correlation between FFM-EBI and FFM-C, a positive and fair correlation was found $(r=0.42 ; p=0.00)$ at 0.01 level of significance (Figure 3). Urinary creatinine excretion rate (CER) is an established marker of muscle mass [35]. When muscle mass is less, urine creatinine level might be slightly lower, because of small stature or little muscle mass, urine creatinine level will likely be lower than normal [36]. This may be the probable reason that the variables are not showing the strong association. As reported earlier that most of the subjects were vegetarian and non-vegetarians were also not consuming non-vegetarian diet very frequently. Protein taken by the subjects was also reported ( $46.3 \pm 11.0 \mathrm{~g} /$ day) to be $77.0 \pm 18.3 \%$ of RDA. It may also influence the creatinine levels due to diet induced creatinine formation [37].

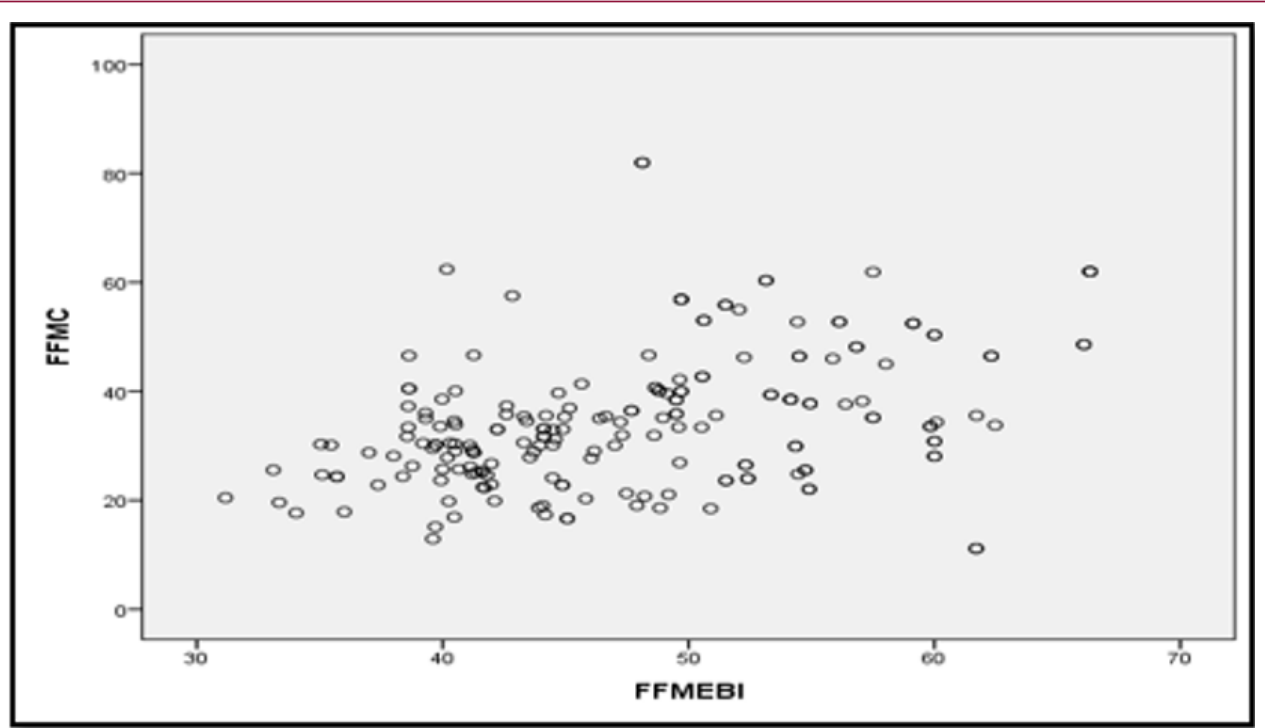

Figure 3: Relationship between FFM-C and FFM-EBI.

Table 4: Mean Creatinine excretion, FFM-EBI and FFM-C of the subjects.

\begin{tabular}{|c|c|c|c|c|}
\hline S.No & Parameters & Men $n=100$ & Women $n=100$ & p value \\
\hline \multirow{2}{*}{1.} & \multirow{2}{*}{ 24HUCrE (mg/day) } & 1128.1 & 748.1 & \multirow{2}{*}{$0.000^{* *}$} \\
\hline & & \pm 453.1 & \pm 286.1 & \\
\hline \multirow{2}{*}{2.} & \multirow{2}{*}{ FFM-EBI (kg) } & 53.1 & 42.3 & \multirow{2}{*}{$0.000^{* *}$} \\
\hline & & \pm 6.5 & \pm 4.5 & \\
\hline \multirow{2}{*}{3.} & \multirow{2}{*}{ FFM-C (kg) } & 40.2 & 29.1 & \multirow{2}{*}{$0.000^{* *}$} \\
\hline & & \pm 13.2 & \pm 8.3 & \\
\hline
\end{tabular}

Table 5: Mean 24HUNaE of the subjects.

\begin{tabular}{|c|c|c|c|c|c|}
\hline \multirow{2}{*}{ S No } & Parameters & Total men $\mathbf{n = 1 0 0}$ & Total women $\mathbf{n = 1 0 0}$ & Total subjects n= 200 & Level of significance \\
\hline \multirow{2}{*}{1.} & \multirow{2}{*}{$24 \mathrm{HUNaE}(\mathrm{mg} / \mathrm{day})$} & 4919.8 & 4672.9 & 4796.3 & \multirow{2}{*}{$0.739 \mathrm{NS}$} \\
\cline { 3 - 6 } & & \pm 3196.7 & \pm 3418.3 & \pm 3303.3 & \\
\hline
\end{tabular}

Note: NS: Non-significant.

Table 6: The World Hypertension League's nomenclature regarding salt intake [46].

\begin{tabular}{|c|c|c|}
\hline S. No. & Dietary salt intake & Considered as \\
\hline 1. & $<0.25 \mathrm{~g} /$ day or $<100 \mathrm{mg} /$ day of sodium & Low \\
\hline 2. & $<2.5 \mathrm{~g} /$ day salt $<100 \mathrm{mg} /$ day sodium & Recommended values \\
\hline 3. & $<5.0 \mathrm{~g} / \mathrm{d}$ salt and $<100 \mathrm{mg} /$ day sodium & High \\
\hline 4. & $>5.0-10 \mathrm{~g} / \mathrm{d}$ or $\geq 2000-4000 \mathrm{mg} /$ day of sodium & Very high \\
\hline 5. & $>10-15 \mathrm{gm} / \mathrm{d}$ of salt or $4000-6000 \mathrm{mg} /$ day of sodium & Extremely high $/$ day of salt or $>6000 \mathrm{mg} /$ day of sodium \\
\hline 6. & &
\end{tabular}




\section{HUNaE of the subjects}

Table 7 exhibited that the mean sodium excreted in subjects was $4796.3 \pm 3303.3 \mathrm{mg} /$ day or in terms of mmol, it was $208.63 \pm 143.55$ in comparison to the recommended amount, $100 \mathrm{mmol} /$ day $(2300$ $\mathrm{mg} /$ day) as recommended by WHO [8]. Sodium excretion in women was $4672.9 \pm 3418.3 \mathrm{mg} /$ day as compared to men $(4919.8 \pm 3196.7$ $\mathrm{mg} /$ day). As results depicted that the figures were exceeding more than twice fold in men and women both. A non-significant difference was found between the sodium excreted of men and women $(p>0.05)$. However, men had higher mean sodium excretion than women. The men were having higher food intake as compared to women, which further supposed to associated with higher salt intake and thus with sodium excretion. In a survey in 2001, the average consumption of salt in the UK, as measured by 24-hour urinary sodium, was $10.9 \mathrm{~g} /$ day in men, whereas in women it was only 8.1g/day [38]. A study conducted in South India concluded that men had higher mean sodium intake $(4.1 \pm 2$ versus $3.2 \pm 1.7$ g/day; $P<0.01)$ with higher mean SBP and DBP (123/77 versus $117 / 74 \mathrm{~mm} \mathrm{Hg} P<0.01)$, and higher prevalence of hypertension (22.2\% versus $12.9 \% ; P<0.01$ ) when compared with women [39].

Table 7: Comparison between dietary sodium intake and monthly salt consumption with $24 \mathrm{HUNaE}$.

\begin{tabular}{|c|c|c|c|}
\hline \multirow{2}{*}{ S No } & \multirow{2}{*}{ Variables } & \multicolumn{2}{|r|}{ Total $(n=200)$} \\
\hline & & t value ( $p$ value) & Correlation coefficient ( $r$ ) ( $p$ value) \\
\hline 1. & Dietary sodium intake & $4.734\left(0.000^{* *}\right)$ & $0.47\left(0.000^{* *}\right)$ \\
\hline 2. & Salt consumption calculated on the basis of monthly household consumption & $6.158\left(0.000^{* *}\right)$ & $0.20\left(0.008^{* *}\right)$ \\
\hline
\end{tabular}

Note: *Significant at 0.05 level; ** Significant at 0.01 level.

When results were further evaluated among the two genders, no significant difference was obtained among two different age groups ( $p>0.05)$. Nevertheless, women in elder age group had higher mean sodium excretion along with wide variation; due to extreme data in the category. The presented data accomplished the higher sodium intake in the region. Further, to provide data for layman in terms of salt, it was assumed that sodium eliminated in the urine was derived from the salt intake only, the excretion would correspond with a dietary salt intake of 12.5 and $11.9 \mathrm{~g} / \mathrm{d}$ for men and women respectively. Conversion of sodium to sodium chloride was carried out as given in the methodology. Evidences were also found to be providing the similar data that obtained in the present study. Most adult populations around the world have average daily salt intakes higher than 6 gram/day and for many in Eastern Europe and Asia higher than 12 grams [7]. An Indian council of medical research survey reported a daily salt intake of 13.8 gram in 13 states in 1986-88 [40]. A study reported the salt intake of $8.5 \mathrm{~g} / \mathrm{d}$ on a representative population of Chennai city in Southern India [41].
Whereas an another study in Kashmir depicted the mean levels of sodium excretion were found to be ranging from $424 \pm 150.50$ $\mathrm{mmol} / \mathrm{d}$ in hypertensive and $337 \pm 121.50 \mathrm{mmol} / \mathrm{d}$ in normotensive that would corresponds to 24.8 and $19.7 \mathrm{~g} / \mathrm{d}$ of salt in hypertensives and normotensives respectively [42]. The HEART study was reported salt intake of $12 \mathrm{~g} / \mathrm{d}$ in Tamil Nadu [43]. Petersen et al reported the salt intake of $8.59 \mathrm{~g} /$ day in Delhi and Haryana and 9.46 g/day in Andhra Pradesh. Twenty four hours urine collection was used for collecting data in the reported study [44]. A study in Punjab reported the very high mean sodium intake $(7.4 \mathrm{~g} /$ day of sodium) assessed by spot urine sodium excretion. It would be equivalent to $18.8 \mathrm{~g} /$ day of salt [45]. The World Hypertension League with other organizations involved in dietary reduction have proposed a standardized nomenclature based on normal levels of salt intake and also ranges of reduction in salt intake in clinical and population intervention. As per The World Hypertension League's nomenclature regarding salt intake [46], it can be considered as very high.

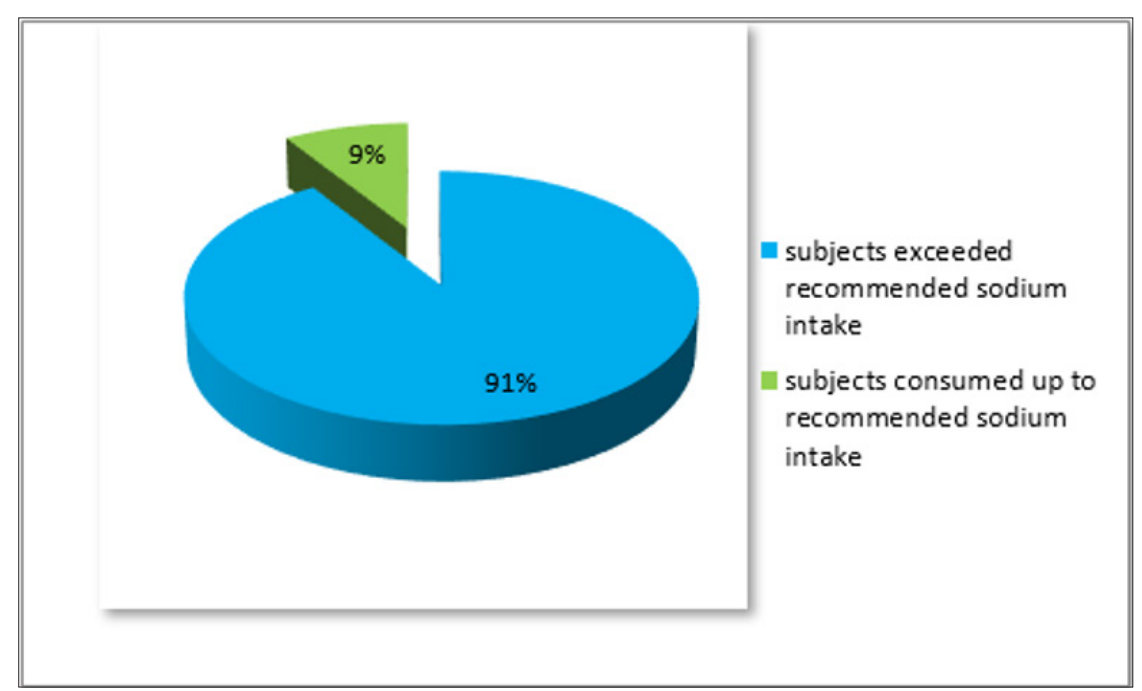

Figure 4: Percent distribution of subjects according to their level of urinary sodium excretion. 
Twenty four hours urinary sodium excretion method does not account for electrolyte loss other than via the kidneys, and therefore will tend to slightly underestimate the true intake, particularly in very hot countries [47]. If approximately $15 \%$ renal loss [48] were to be included, the overall salt intake would be 14.4 and $13.7 \mathrm{~g} / \mathrm{d}$ for men and women respectively. It would also correspond to nearly $13.8 \mathrm{~g} / \mathrm{d}$ for total subjects. In terms of salt, it should not exceed the $5 \mathrm{~g} / \mathrm{d}$ as suggested by WHO [8]. The results indicated the requirement of a meaningful strategy to reduce salt consumption in the region. People in the region generally love to have salty and spicy foods [49], it was not surprising to find the high sodium consumption in comparison to the existing data that reports the consumption of 9-12 g/d of salt in other areas. Preference for salty foods was positively associated with the daily salt intake [50]. Majority of subjects (91.0\%) were exceeding the recommended sodium consumption, when analyzed on the basis of 24HUNaE (Figure 4). According to WHO [8], it should be less than $2000 \mathrm{mg} /$ day.

Evidences demonstrated that dietary recall tend to underestimate sodium intakes since only a portion of sodium can be captured by dietary assessment. The 24-hour urinary sodium excretion is considered the gold standard method to estimate intake since $85-90 \%$ of ingested sodium is excreted through the kidneys and provide an estimate of total sodium intake from all sources [51]. Since $24 \mathrm{HUNaE}$ is a cumbersome technique to measure sodium consumption in a population and it was expensive too, thus Pearson's correlation was calculated to obtain any association between dietary sodium intake and 24HUNaE.Estimation of sodium consumption at population level is fundamental for planning and monitoring salt reduction policies nation-wide and the gold standard method is based on a $24 \mathrm{~h}$ urine collection from a random community sample. Surveys of this type are, however, complex and expensive and because participant burden is high, randomly selected community samples typically have low response rates [5254]. Mean $24 \mathrm{HUNaE}$ (4796.3 $\pm 3303.3 \mathrm{mg} /$ day) values were higher than the mean dietary sodium intake $(3840.6 \pm 1810.1 \mathrm{mg} /$ day $)$. The difference was found statistically significant $(p=0.000)$. Yet a significant correlation was observed between two variables $(r=0.47$; $\mathrm{p}=0.000$ ). As stated earlier, dietary survey tend to underestimate sodium intakes and reporting biasness can also be there. Further, a significant difference was observed between sodium values obtained by $24 \mathrm{HUNaE}$ method and sodium estimation on the basis of monthly household consumption of salt. A positive but week association was found between two variables $(p<0.05)$.

\section{Conclusion}

The high sodium intake reported in the study is very alarming. Reducing sodium needs be a priority on the public health strategy agenda. Salt reduction can save a lot of lives if implemented as a systematic and sustained campaign. This will be achieved through the implementation of an education and public awareness campaign and by engaging food and meal producers and distributors to reformulate their products. Effective monitoring and evaluation of sodium consumption may require an efficient food composition databases which will help in monitoring not only sodium intakes but also the sources of sodium. With nutrition transition sodium consumption is higher; multinational food companies are specifically targeting developing economies for expanding their markets. There is a need for concerned action from government, civil society, public health experts, academia, and food and beverage industries. Sodium consumption level is now available for many nations whereas such estimates are still not available in most of the regions of India. By providing evidence about how much salt people are consuming, it can draw attention that how much of salt they should cut off from their daily consumption.

The dietary survey can also point out to the sources of sodium, whether it is at household level or at the industry level in processed and ready to eat foods. Thus, before proceeding to any effective strategy, data regarding sodium consumption is critical in facilitating the development and implementation of an India-specific salt reduction programme, to translate the existing scientific evidence into the population health gains, and also to subsequently monitor and evaluate such a programme. On the basis of the results obtained by the study it can be concluded that 24 hours urinary sodium excretion is the best method to assess the sodium consumption at population level. WHO also advocated it as a "gold standard method" to estimate the sodium consumption at population level. Dietary recall method was found to under report the sodium consumption due to biased reporting and errors in weighing or standardization of the recipe. Due to the high participant burden of 24-h urine collection, other urine specimens, such as spot/casual, overnight, and timed 12-h collections, can also be explored. But due to poor correlation with 24 hours urinary sodium excretion, evidences are not prescribed to use these to estimate sodium consumption at population level.

\section{Acknowledgement}

My special acknowledgements go to all my subjects who voluntarily participated in my study and made possible the difficult task of "24 hours urine sample collection" for the research. I acknowledge the UGC, New Delhi and SAP under department of Home Science, University of Rajasthan for providing financial assistance in the form of UGC-BSR Fellowship.

\section{References}

1. Global Burden of Diseases 2013 Mortality and Causes of Death Collaborators (2015) Global, regional, and national levels of age -sex specific all -cause and cause -specific mortality for 240 causes of death, 1990-2013: A systematic analysis for the Global Burden of Disease Study 2013. Lancet 385: 117-171.

2. GBD 2016 Risk Factors Collaborators (2017) Global, regional, and national comparative risk assessment of 84 behavioral, environmental and occupational, and metabolic risks or clusters of risks, 1990-2016: A systematic analysis for the Global Burden of Disease Study 2016. Lancet pp. $1345-1422$. 
3. National Health Profile (2018) Central Bureau of Health Intelligence, Dte. General of Health Services, Ministry of Health \& Family Welfare.

4. Inoue H, Miyashita K, Sato M, Hagiwara A, Fujii K, et al. (2018) Transient salt loading causes persistent hypertension through epigenetic modification of the renal arterioles. J Hypertens 36(1): e186.

5. Bhansali A, Dhandhania VK, Deepa M (2015) Prevalence of and risk factors for hypertension in urban and rural India: the ICMR-INDIAB study. J Hum Hypertens 29(3): 204-209.

6. NIN (2011) Dietary guidelines for Indians - A manual. National Institute of Nutrition. Indian council of Medical Research, Hyderabad, India.

7. He FJ, MacGregor GA (2009) A comprehensive review on salt and health and current experience of worldwide salt reduction programmes. J Hum Hypertens 23: 363-384.

8. WHO (2007) Reducing salt intake in populations: report of a WHO forum and technical meeting. Pp. 5-7.

9. (2010) WHO/PAHO regional expert group for cardiovascular disease prevention through population-wide dietary salt reduction (2010). Protocol for population level sodium determination in 24 hour urine samples p. 1-40.

10. Institute of Medicine (2010) A population-based policy and systems change approach to prevent and control hypertension. Washington, DC: National Academies Press.

11. Thompson FE, Subar A (2013) Dietary assessment methodology. In Nutrition in the Prevention and Treatment of Disease ( $3^{\text {rd }}$ edn.). p. 5-46.

12. Loria CM, Obarzanek E, Ernst ND (2001) Choose and prepare foods with less salt: dietary advice for all Americans. J Nutr 131:536-551.

13. WHO (2011) Waist-circumference and waist-hip ratio. Report of a WHO expert consultation Geneva. pp. 8-11.

14. WHO Expert Consultation (2004) Appropriate body-mass index for Asian populations and its implications for policy and intervention strategies 363: 157-163.

15. Longvah T, Ananthan R, Bhaskarachary K (2017) Indian food composition tables. National Institute of Nutrition. Indian Council of Medical Research. Department of Health Research. Ministry of Health and Family Welfare.

16. McLean R, Hoek J (2014) Sodium and nutrition labeling: A qualitative study exploring New Zealand consumer's food purchasing behaviours. Pub Health Nutri 17(5): 1138-1146.

17. Espeland MA, Kumanyika S, Wilson AC (2001) TONE Cooperative Research Group. Statistical issues in analyzing 24-h dietary recall and 24-h urine collection data for sodium and potassium intakes. Am J Epidemiol 153: 996-1006.

18. Clark AJ, Mossholder S (1986) Sodium and potassium intake measurements: dietary methodology problems. Am J Clin Nutr 43: 470476.

19. Ortega RM, Sobaler AML, Ballesteros JM (2010) Estimation of salt intake of 24-h urinary sodium excretion in a representative sample of Spanish adults. British J Nutr p. 1-7.

20. Panda PS, Jain KK, Soni GP (2017) Prevalence of hypertension and its association with anthropometric parameters in adult population of Raipur city, Chhattisgarh, India. Int J Res Med Sci 5(5): 2120-2125.

21. Zhang Q Mahapatra T, Huang F (2017) Association between anthropometric measurements and indicators for hypertension control among Kazakh-Chinese hypertension patients in Xinjiang, China: results from cross-sectional study. PloS ONE 12(1): e0170959.

22. Chen D, Rivera-Andrade A, González J (2017) Prevalence of risk factors for non-communicable diseases in an indigenous community in Santiago Atitlan, Guatemala. Rev Panam Salud Publica 41: e7.

23. Rocha SV, Mota J, Furtado G (2017) Association between body mass index and chronic non-communicable diseases among the elderly chronic diseases, body mass index and elderly. MOJ Gerontol Ger 1(5): 120-126.

24. Taing KY, Farkouh ME, Moineddin R (2017) Comparative association between anthropometric and bioelectric impedance analysis derived adiposity measures with blood pressure and hypertension in India: a cross-sectional analysis. BMC Obesity 4: 37

25. Faria TC, Giannini DT, Gasparini PVF (2018) Heart failure: correlation between anthropometric parameters, body composition and cell integrity. Int J Cardiovasc Sci 31(3): 226-234.

26. Nagar SR, Jain M (2017) Study to assess predictive value of waist to height ratio and body mass index as a risk factor of hypertension and type 2 diabetes mellitus. Int J Community Med Public Health 4(4): 1099 1103.

27. Lotfi MH, Saadati H, Afzali M (2014) Association between anthropometric parameters (WC, BMI, WHR) and type 2 diabetes in the adult Yazd population, Iran. J Diabetes Metab 5: 444.

28. Singh RB, Balaji S, Niaz MA (1992) Prevalence of type 2 diabetes mellitus and risk of hypertension and coronary artery disease in rural and urban population with low rates of obesity. Int J Cardiol 66: 65-72.

29. Dudeja V, Misra A, Pandey RM (2001) BMI does not accurately predict overweight in Asian Indians in northern India. Br J Nutr 86: 105-112.

30. NNMB (2012) National nutrition monitoring bureau: diet and nutritional status of rural population, prevalence of hypertension and diabetes amon adults and infant and young child feeding practices; report of third repeat survey.

31. Mizehoun-Adissoda C, Houehanou C, Chianea T (2016) Estimation of daily sodium and potassium excretion using spot urine and 24 hour urine samples in a black population (Benin). J Clin Hypertens (Greenwich) 18(7): 634-640.

32. Brown IJ, Tzoulaki I, Candeias V (2009) Salt intakes around the world: implications for public health. Int J Epidemiol 38: 791-813.

33. Bingham SA, Cummings JH (1985) The use of creatinine output as a check on the completeness of 24-hour urine collections. Hum Nutr Clin Nutr 39: 343-353.

34. Webster J, Garrow JS (1985) Creatinine excretion over 24 hours as a measure of body composition or of completeness of urine collection. Hum Nutr Clin Nutr 39: 101-106.

35. Hsu CY, Wu YL, Cheng CY (2015) Low Baseline Urine Creatinine Excretion Rate Predicts Poor Outcomes among Critically Ill Acute Stroke Patients. Curr Neurovasc Res 12(1): 47-52.

36. University of Rochester Medical Centre (2018) Health encyclopedia. Creatinine (Urine).

37. Oterdoom LH, Gansevoort RT, Schouten JP (2009) Urinary creatinine excretion, an indirect measure of muscle mass, is an independent predictor of cardiovascular disease and mortality in the general population. Atherosclerosi 207(2): 534-540.

38. Henderson L, Irving K, Gregory L (2003) National Diet and Nutrition Survey: adults aged 19 to 64- vitamin and mineral intake and urinary analytes. A survey carried out in Great Britain on behalf of the Food Standards Agency and the Departments of Health by the Social Survey Division of the office for National Statistics and Medical Research Council Human Nutrition Research 3: 127-136.

39. Ravi S, Bermude OI, Harivanzan VK (2016) Sodium intake, blood pressure, and dietary sources of sodium in an adult South Indian population. Ann Glob Healt 82(2): 234-242.

40. Kalra S, Sahay M, Baruah MP (2013) Reducing Salt Intake for Healthier World. J Med Nutr and Nutraceuticals 2: 1-2.

41. Radhika G, Sathya RM, Sudha V (2007) Dietary salt intake and hypertension in an urban South Indian population [CURES-53]. JAPI 55: 405-411. 
42. Jan RA, Shah S, Saleem SM, Waheed A, Mufti S, et al. (2006) Sodium and potassium excretion in normotensive and hypertensive population in Kashmir. JAPI 54: 22-26.

43. Chidambaram N, Sethupathy S, Saravanan N (2014) Relationship of sodium and magnesium intakes to hypertension proven by 24 -Hour Urianalysis in a South Indian Population. J Clin Hypertens 16(8): 581 586.

44. Peterson KS, Johnson C, Mohan S (2017) Estimating population salt intake in India using spot urine samples. J Hypertens 35(11): 22072213.

45. Thakur JS, Jeet G, Pal A (2016) Profile of risk factors for noncommunicable diseases in Punjab, Northern India: Results of a statewide STEPS survey. PLoS ONE 11(7): e0157705.

46. Campbell NRC, Lackland DT, Lisheng L (2015) The world hypertension league: where now and where to in salt reduction. Cardiovasc Diagn Ther 5(3): 238-242.

47. Hawkes C, Webster J (2012) National approaches to monitoring population salt intake: A trade-off between accuracy and practicality. Plos One 7(10): e46727.

ISSN: 2574-1241

DOI: 10.26717/BJSTR.2018.11.002096

Sonal Dhemla. Biomed J Sci \& Tech Res

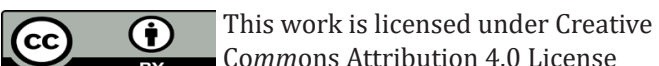

Submission Link: https://biomedres.us/submit-manuscript.php
48. Ovesen L, Boeing H (2002) The use of biomarkers in multicentric studies with particular consideration of iodine, sodium, iron, folate and vitamin D. Eur J Clin Nutr 56(2): S12-S17.

49. Dhemla S, Varma K (2016) Estimation of salt intake of normotensive subjects of Jaipur city. Nutri Food Sc 46(6): 766-777.

50. Takamura K, Okayama M, Takeshima T (2014) Influence of salty food preference on daily salt intake in primary care. Intern J Gen Med 7: 205210 .

51. Liu ZM, Ho SC, Tang N (2014) Urinary sodium excretion and dietary sources of sodium intake in Chinese postmenopausal women with prehypertension. PLoS ONE 9(8): e104018.

52. Ribic CH, Zakotnik JM, Vertnik L (2010) Salt intake of the Slovene population assessed by $24 \mathrm{~h}$ urinary sodium excretion. Public Health Nutr 13: 1803-1809.

53. Chappuis A, Bochud M, Glatz N (2011) Swiss survey on salt intake: main results.

54. Ortega RM, Lopez-Sobaler AM, Ballesteros JM (2011) Estimation of salt intake by $24 \mathrm{~h}$ urinary sodium excretion in a representative sample of Spanish adults. Br J Nutr 105: 787-794.

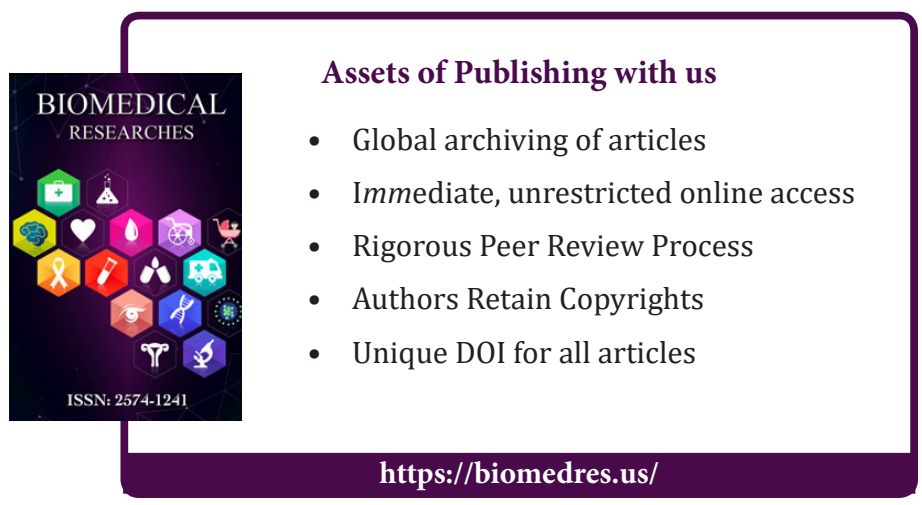

